\title{
BALLOON OCCLUSION OF THE INTERNAL ILIAC ARTERIES IN THE MULTIDISCIPLINARY MANAGEMENT OF PLACENTA ACCRETA AT ZAGAZIG UNIVERSITY HOSPITALS
}

\author{
Mostafa S. Mostafal M.D. ${ }^{\text {a }}$; Ahmed M. El-hosseiny M.D. ${ }^{\text {a }}$; Awad A. Bessar M.D. ${ }^{\text {b }}$; Sameh M. Saber \\ M.D. ${ }^{b}$; Ahmed A. Bessar M.D. ${ }^{\text {; }}$ Ahmed H. El-maasrawy M,.Sc ${ }^{a}$ \\ ${ }^{a}$ Obstetrics and Gynecology , Faculty of medicine, Zagazig University. \\ ${ }^{b}$ diagnostic radiology , Faculty of medicine, Zagazig University .
}

Corresponding author:

Ahmed H. Elmaasrawy

ahmed.elmaasrawy@yahoo.com

\section{ABSTRACT}

Objective: The aim of this work to evaluate the efficacy of temporary balloon occlusion of the internal iliac arteries in reducing intraoperative blood loss and blood transfusion requirements in caesarean hysterectomy in pregnant women with prenatal diagnosis of placenta accreta.

Methods: Thirty patients who were admitted in high risk pregnancy unit, obstetric department, Zagazig university hospitals with prenatal diagnosis of placenta accreta had been included in this one step random assignment control trial over the period from June 2015 to June 2017.All cases were diagnosed by ultrasonography, color Doppler imaging and supplemented with MRI where necessary. The patients included in the study were divided randomly into two groups; Group A (case): In this group prophylactic temporary balloon occlusion of internal iliac arteries was done followed by CS hysterectomy. Group B (control): In this group CS hysterectomy was done and internal iliac artery ligation was done in selected cases. Intraoperative blood loss, Volume of blood transfused $(\mathrm{ml})$, perioperative hemoglobin change (g/dl), Duration of surgery (min), Length of hospitalization (d), Duration of ICU admission (d) were recorded and compared in both groups ; Fluoroscopy, balloon occlusion time, any complication arisen during the procedure of balloon occlusion also were recorded.

Results: The mean intraoperative blood loss in the balloon group (A) (1315 mL; range, $800-2500 \mathrm{~mL}$ ) was significantly less than in the control group (B) $(1766.7 \mathrm{~mL}$; range, $850-3500 \mathrm{~mL})(\mathrm{p}=0.04)$. The mean volume of blood transfused was significantly less in the balloon group than in the control group $(\mathrm{p}=0.03)$. There was also significant difference in the perioperative change in hemoglobin levels $(\mathrm{p}=$ $0.04)$.There were no significant differences regarding operation time $(\mathrm{p}=0.83)$, length of hospitalization $(\mathrm{p}=0.27)$, or ICU admission $(\mathrm{p}=$ 0.64). Mean fluoroscopy time was $9.20 \mathrm{~min}$; balloon occlusion time was 116.30 min with no reported maternal or fetal complications related to balloon procedure.

Conclusions: The results demonstrated that prophylactic balloon occlusion of internal iliac artery is a safe method and appears to reduce blood loss and transfusion requirements in patients diagnosed with placenta accreta who undergo cesarean hysterectomy. Antenatal imaging diagnosis of placenta accreta enables preoperative planning.

Key words: Internal Iliac artery occlusion; balloon occlusion; placenta accreta, morbidly adherent placenta; postpartum hemorrhage; caesarean hysterectomy.

\section{INTRODUCTION}

P lacenta accreta is the abnormal adherence of the placenta to the uterine wall and depending on the degree of invasion into the myometrium, is classified as placenta accreta vera, increta or percreta. The incidence is about 1 in 500 but is a life-threatening condition with a maternal morbidity rate of $7 \%$. Approximately $90 \%$ of patients required 


\section{Mostafa et al}

blood transfusion (1). With many countries around the world reporting an increasing rate of caesarean sections, this condition is indeed worrying and expected to rise (2).

Prenatal diagnosis of placenta accreta using ultrasound and/or magnetic resonance imaging in imaging in high-risk populations is feasible, and can improve both maternal and neonatal outcomes via a delivery planning process led by an experienced obstetric team including anesthesiologists, senior gynecologists, neonatologists, urologists and interventional radiologists(3).

The jury is still out on the optimal management of placenta accreta but the majority of cases would involve a caesarean hysterectomy, which is considered the current standard treatment. In fact, it has been reported that up to two in five peripartum hysterectomies are related to placenta accreta. Large amount of intraoperative blood loss is common (3000mls or more) and many techniques therefore, have been developed to address this (4).

Prophylactic balloon occlusion of the internal iliac arteries as an adjunct was first described by Dubois and since then, has resulted in mixed outcomes in patients diagnosed with placenta accreta, making it a controversial procedure (5). The advantages of this technique are a reduction in blood loss and improved visualization of the surgical field, until hemostasis is achieved or hysterectomy performed. Intrapartum and postpartum hemorrhage could be also prevented, hence reducing the need for blood transfusion (6).

\section{PATIENTS AND METHODS}

Thirty singleton pregnant women with placenta accreta or its variants (diagnosed by gray scale U\&S, color Doppler U\&S and (or) MRI after 28 week's gestation) who were admitted in high risk pregnancy unit, obstetric department, Zagazig university hospitals with prenatal diagnosis of placenta accreta had been included in this one step random assignment control trial over the period from June 2015 to June 2017.

Exclusion criteria included any case terminated by emergency C.S hysterectomy, multifetal gestation, allergy to contrast media,

\section{Zagazig University Medical Journals}

BMI >30 and co existing high risk pregnancy eg. HELLP syndrome, bleeding disorders.

The patients included in the study were divided randomly into two groups by lottery box containing numbers from 1 to 30 as odd number were in group (A) and even number were in group $(\mathbf{B})$ :

Group A (case): In this group prophylactic temporary balloon occlusion of internal iliac arteries was done followed by CS hysterectomy.

Group B (control): In this group CS hysterectomy was done and internal iliac artery ligation was done in selected cases.

All women were subjected to the following:

A. History taking: including age, gravidity, parity, date of last menstrual period, present history, past history, obstetric history (history of uterine curettage, previous CS, prior morbidly adherent placenta), gynecological history (history of previous myomectomy, hysteroscopic surgery, history of blood transfusion and allergy to contrast media used in group (A).

B. Clinical examination: including general and obstetric examination.

C. Ultrasound examination: Ultrasound was performed using ((GE voluson healthcare Austria with $5 \mathrm{MHz}$ curvilinear probe for TAS\& $7.5 \mathrm{MHz}$ sector transducer for TVS).

The following U\&S criteria were adopted to diagnosis of placenta accreta : (fig 1)

Deficiency of retroplacental sonolucent zone, placental vascular lacunae, myometrial thinning, interruption of bladder line and presence of exophytic masses.

On Color Doppler ultrasound; diffuse lacunar flow pattern with high-velocity pulsatile venous type flow (peak systolic velocity more than $15 \mathrm{~cm} / \mathrm{s}$ ) spread throughout the placenta, myometrium and cervix, bladder-uterine serosal interphase hyper vascularity and markedly dilated vessels over the peripheral sub placental zone.

D. Magnetic resonance imaging: Pelvic MRI was performed using a $1.5 \mathrm{~T}$ machine (Philips-Achieva system) without intravenous Gadolinium injection in selected cases where diagnosis of 


\section{Mostafa et al}

placenta accreta is only suspicious by US but can't be confirmed.

The following MRI criteria were adopted to diagnosis of placenta accreta:

Uterine bulging, heterogeneous signal intensity within the placenta and dark intraplacental bands on T2-weighted images.

\section{E. Procedures:}

1. A multidisciplinary team including a senior obstetrician and assistant, senior anesthesiologist, an urologist, a neonatologist and interventional radiologist were involved in the operation.

2. Cross-matched blood was prepared for each patient at least four units of packed RBCs and two unit plasma.

3. Preoperative application of IIA balloon catheter in group (A) patients, this was done in radio diagnosis department, intervention radiology suite, under fluoroscopy (fig 2). Bilateral femoral arteries access was performed using Seldinger's technique, this involved bilateral femoral arterial punctures and insertion of 8French vascular sheaths under local anesthesia. Over a 0.035-french hydrophilic guide wire (Terumo), a 5-French diagnostic copra shaped catheter (Boston Scientific) was used to reach the contralateral internal iliac artery. The hydrophilic guide wire replaced by a stiff one and the diagnostic catheter is then exchanged for $6-10-\mathrm{mm}$ size, $40 \mathrm{~mm}$ length French occlusion balloon catheter (Wanda standard, Boston Scientific). Size selected according to the vessels caliber.

Balloon catheters positioned with their inflatable part within the anterior division of the internal iliac artery, the procedure was repeated on the other side (fig 3). After both balloon catheters were properly inserted, The Encore 26TM inflator syringes were then attached to both catheters and test volume of dilute water-soluble contrast material was injected to inflate the occlusion balloons (fig 4) then deflated again.

4. After the catheters were secured, the fetal viability and fetal heart rate were recorded by the US; the patients were subsequently taken into the operating room for planned delivery.

5. Under general anesthesia the procedure began with an infraumbilical longitudinal incision (fig 5) to open the peritoneal

\section{Zagazig University Medical Journals}

cavity and vertical incision in the upper uterine segment for delivery of the fetus, and clamping of the umbilical cord.

6. After fetal delivery, the occlusion balloons were inflated guided by C- ARM, (fig 6) and an attempt was made to detach the placenta by administration of oxytocin, ergometrin and application of controlled cord traction. Then, if diagnosis of placenta accreta or its variants was confirmed during the surgery, we proceeded directly to caesarian hysterectomy was done. No attempt was made to expel or manually remove the placenta when it was evident that it had reached the uterine serosa (fig 5).

7. The balloons were deflated just before closure of the rectus sheath after confirming that hemostasis within the pelvis was secured. The balloon catheters were left in place for 24 hours after surgery for fear of primary post-operative bleeding. After 24 hours removal of the balloon catheter and the sheaths, Firm dressing compression over the insertion site was performed for at least $20 \mathrm{~min}$ in all cases.

8. .In group (B) patients the same steps were done as in group (A) but without use of occlusion balloon catheters. Bilateral internal iliac artery ligation was done in selected cases as a prophylactic in morphological apparent placenta percreta or as a therapeutic where bleeding cannot be controlled.

In the internal iliac artery ligation group, adequate exposure was obtained by opening the peritoneum over the bifurcation of the common iliac arteries and internal iliac artery ligation was carried 3-4 cm distal to this level to avoid the posterior division. A right-angle clamp was carefully passed just beneath the artery from lateral to medial. Silk suture was passed under the artery with the clamp and the vessel was then double ligated.

\section{F. Data collected:}

The following parameters were recorded and compared in both groups:

Actual blood loss (ABL) (ml) was calculated by application of modified.

Gross formula ABL = BV [Hct (i) - Hct (f)]/ Hct (m) $(7,8)$. 


\section{Mostafa et al}

Where BV is the blood volume calculated from the Body Weight

(Blood Volume $(\mathrm{ml})=$ Body Weight in $\mathrm{Kg} \mathrm{x}$ 70)

Hct (i), Hct (f) and Hct (m) were the initial, final and mean (of the initial and final) Hematocrits respectively.

Final Hct is measured 2 hours postoperative and subtracting $3 \%$ to every 1 unit packed RBCS.

- Blood loss in the operating room was calculated by:

a. Weigh a dry swab.

b. Weigh blood soaked swabs as soon as they were discarded and subtract their dry weight (1 $\mathrm{ml}$ of blood weighs approximately1 gm).

\section{Zagazig University Medical Journals}

c. Subtract the weight of empty suction bottles from the filled ones).

d. Blood loss into surgical drapes, together with the pooled blood beneath the patient and onto the floor was estimated.

e. The final blood loss was calculated by subtracting the volume of the irrigation fluids from the volume of measured blood loss.

- Volume of blood transfused (ml), perioperative hemoglobin change ( $\mathrm{g} / \mathrm{dl})$, Duration of surgery (min), Length of hospitalization (d), Duration of ICU admission (d) and any complication during the procedure of balloon occlusion.

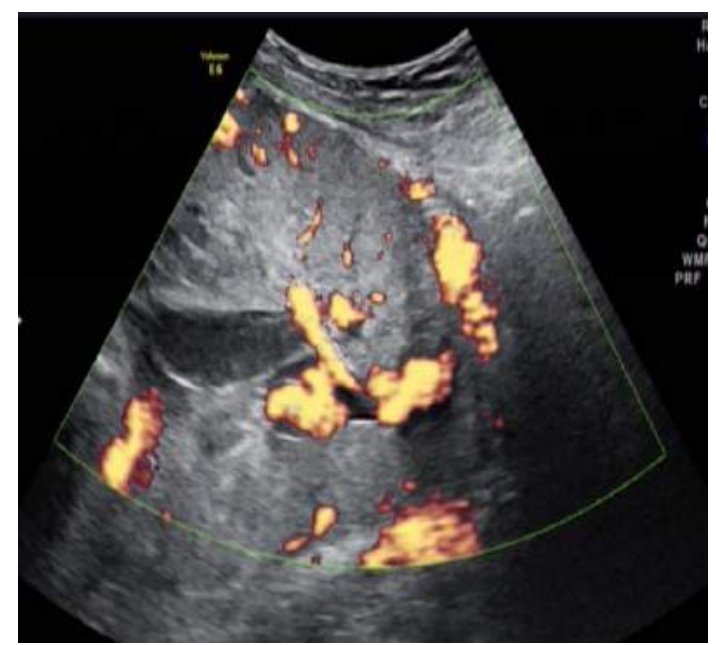

(a)

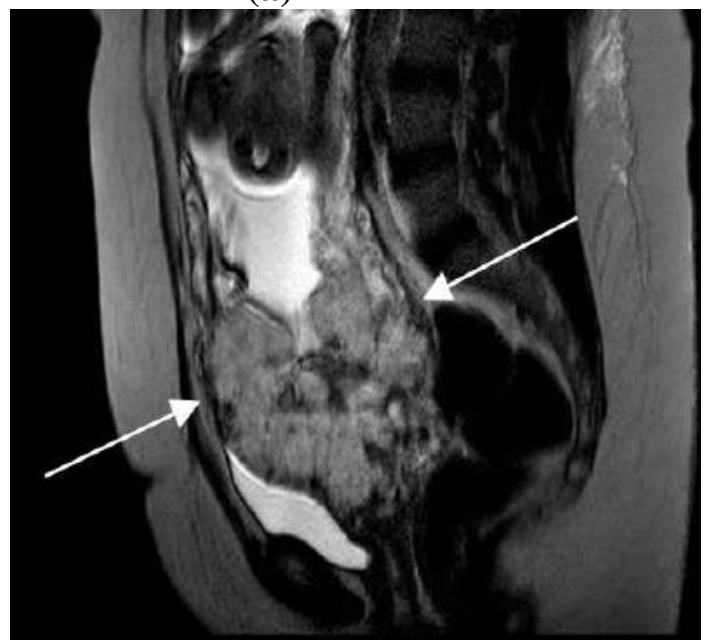

(c)

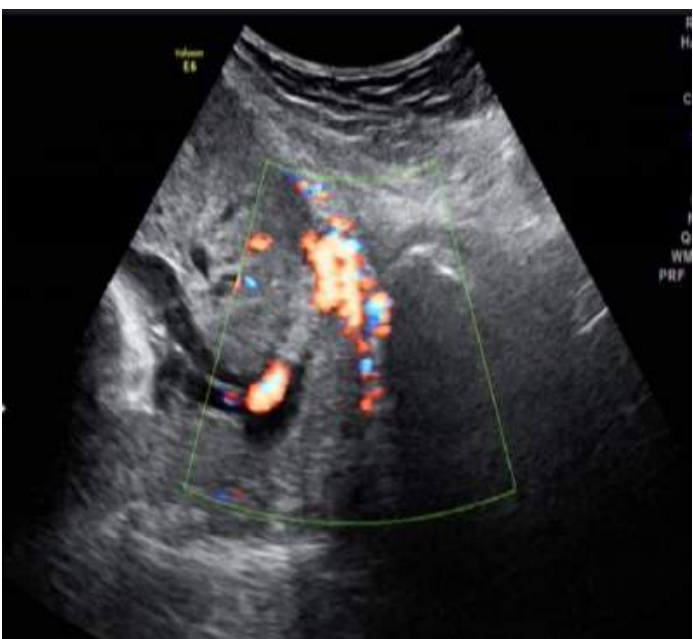

(b)

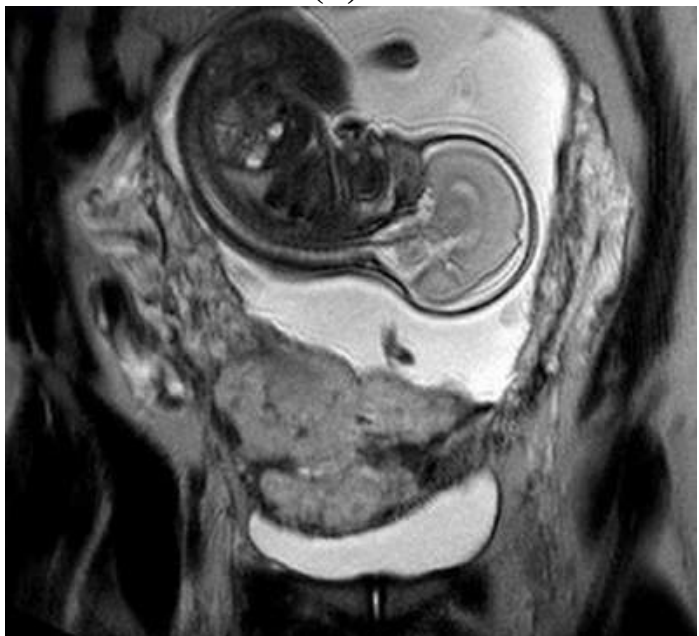

(d)

Fig. (1): Power \& color Doppler US (a, b) suspecting interruption of the retro-placental clear space with lacunar flow \& hypervascularity of the uterine serosa-bladder interface. MRI sagittal \& coronal T2-weighted FSE (c, d) showing abnormally thickened \& heterogeneous placenta with multiple intraplacental dark bands, lower segment anterior \& posterior uterine bulge with interruption of the anterior\& posterior uterine walls (arrows). 


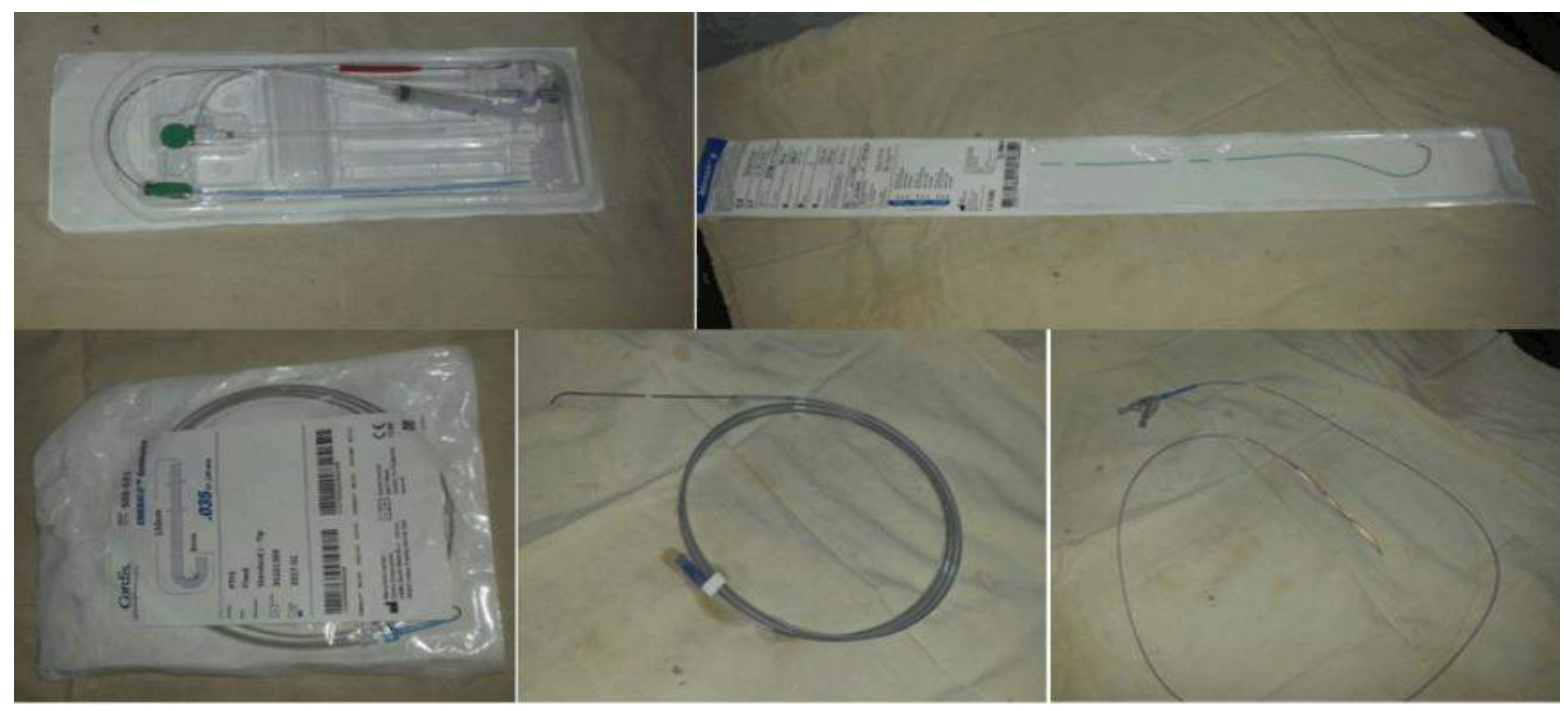

Fig. (2): The endovascular instruments used including the vascular sheath, the diagnostic copra catheter, the stiff wire, the hydrophilic guidewire and the balloon catheter.

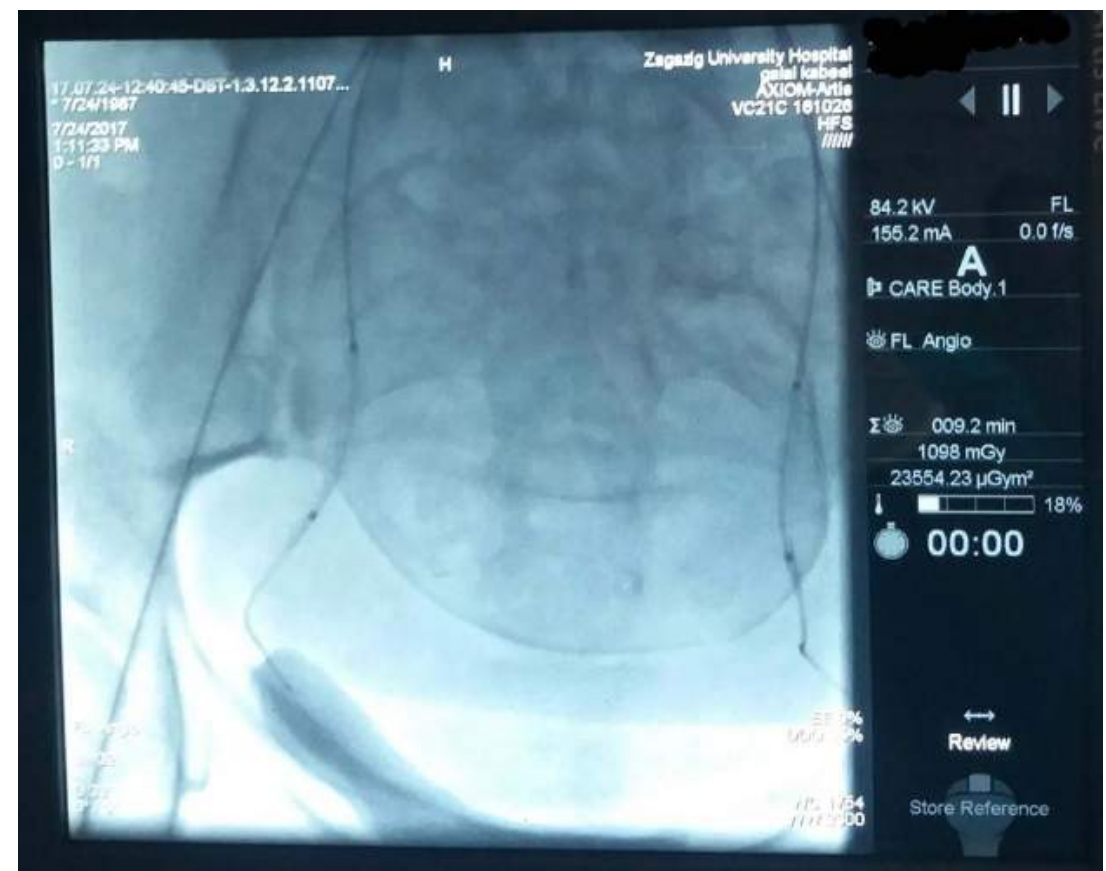

Fig. (3): Bilateral balloon insertion inside anterior division of internal iliac artery under fluoroscopy. 


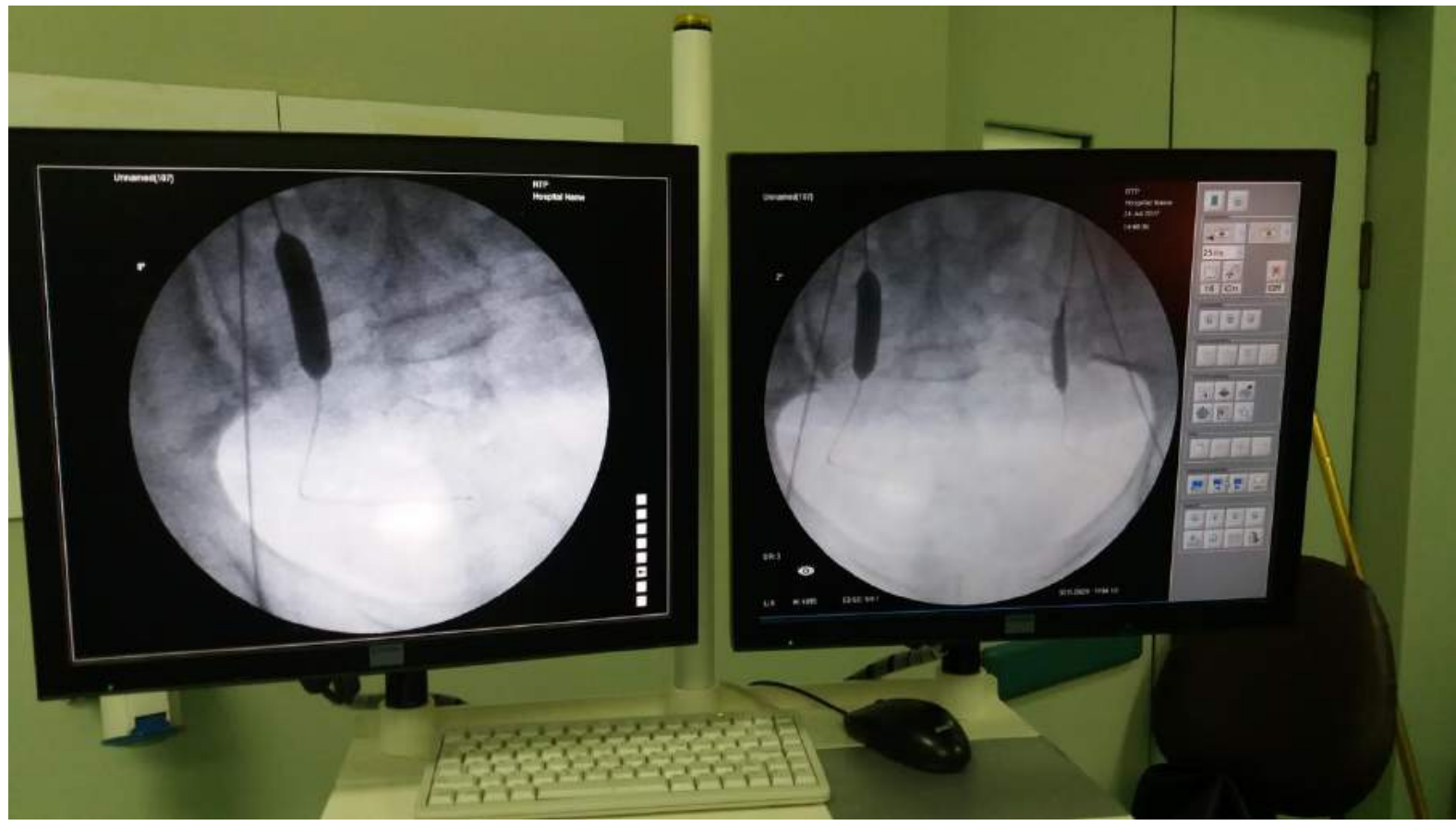

Fig. (4): Test inflation of internal iliac balloon pre delivery under fluoroscopy.
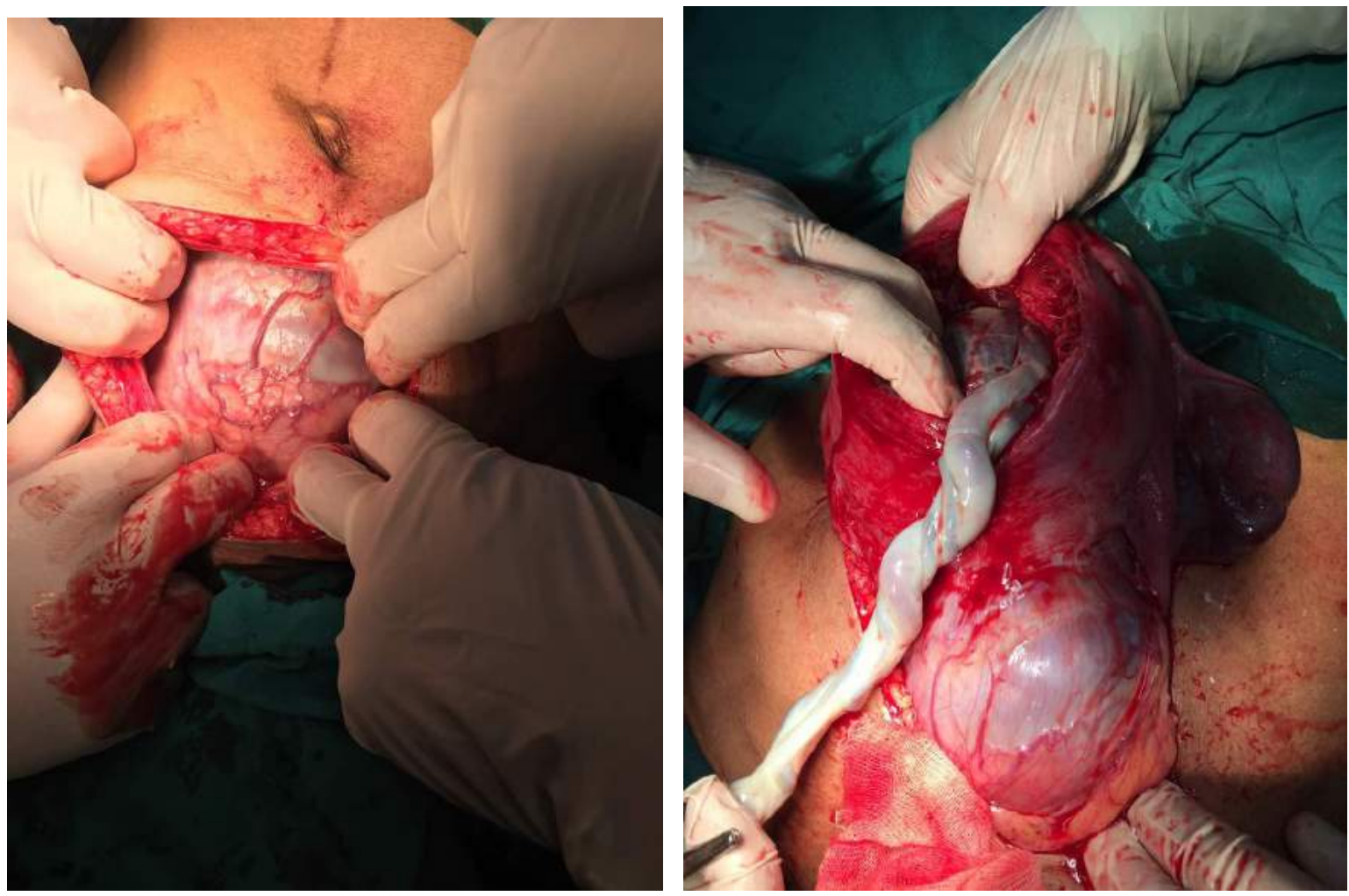

Fig. (5): Intraoperative confirmation of placenta percreta though midline infraumblical skin incision and delivery of the baby through upper segment CS. 


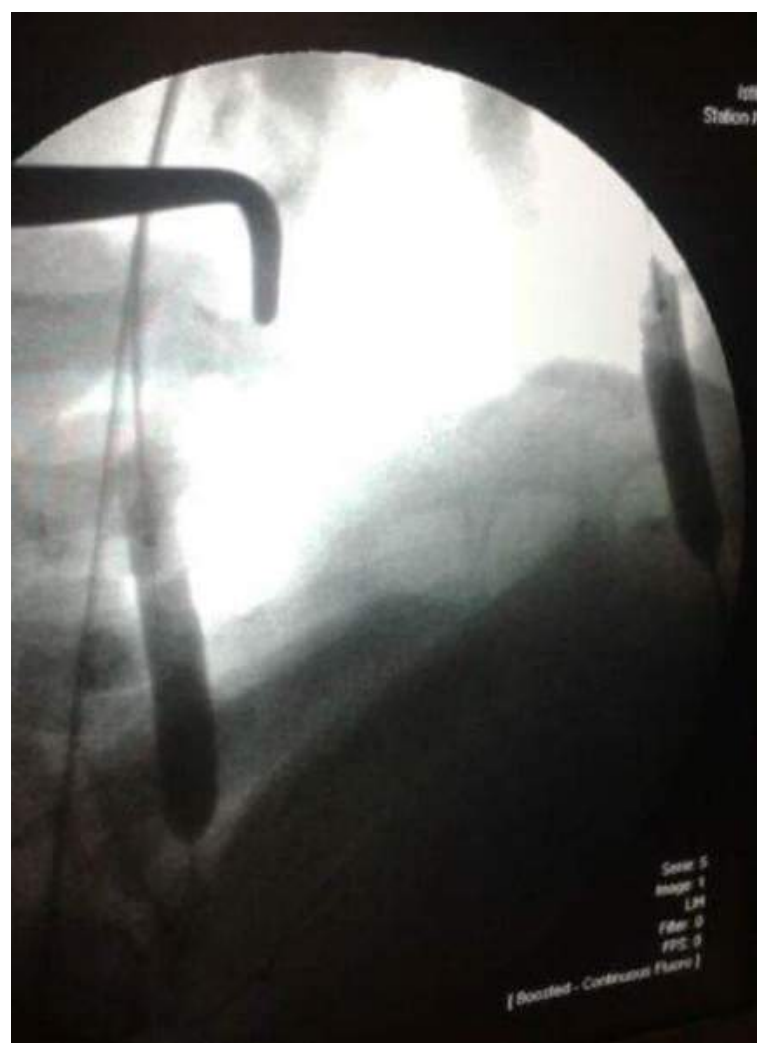

Fig. (6 ): Inflation of internal iliac balloon after delivery of the baby under C-ARM.

\section{Statistical Analysis}

Data were statistically described in terms and mean \pm standard deviation $( \pm \mathrm{SD})$. For comparing categorical data, chi Square(X2) test and Mann-Whitney U-test were performed. $\mathrm{P}$ value less than 0.05 were considered statistically significant. All statistical calculations were done using computer program SPSS (Statistical package for the Social Science).

This study had been approved by Institutional Review Board (IRB), Zagazig University; all the included cases gave informed consents.

\section{RESULTS}

Thirty patients who were admitted in high risk pregnancy unit, obstetric department, Zagazig university hospitals with prenatal diagnosis of placenta accreta had been included in this one step random assignment control trial.
The patients included in the study were divided randomly into two groups by lottery box containing numbers from 1 to 30 as odd number were in group (A) and even number were in group $(\mathbf{B})$ :

Group A (case): In this group prophylactic temporary balloon occlusion of internal iliac arteries was done followed by CS hysterectomy.

Group B (control): In this group CS hysterectomy was done and internal iliac artery ligation was done in selected cases.

There were no statistical significance differences between the two studied groups regarding age, gravidity, parity and gestational age at time of delivery. Further more apparent risk factors for placenta accreta as previous CS or uterine surgery were not statistically different between studied groups (Table 1).

There were no statistical significance differences between the two studied groups in US or intraoperative diagnosis of placenta accreta type. Also there were 
statistical significant agreement between US and interoperation results in both studied groups (Table 2).

Regarding balloon insertion time in Group I it ranged from 15 to 22 min with mean $18 \mathrm{~min}$, mean fluoroscopy time was $9.20 \mathrm{~min}$ and intraoperative occlusion time ranged from 70 to $190 \mathrm{~min}$ with mean $116.33 \mathrm{~min}$ and there was no statistical significance difference in operation time between studied groups Also the actual blood loss, estimated blood loss and in amount of blood transfusion units were significantly less in Balloon group (group I) compared to control group (group II). In addition degree of drop of $\mathrm{HB}$ concentration was significantly less in Balloon group (group I) compared to control group (group II). Finally bilateral IIA ligation was done in 6 cases in control group (Table $3 \& 4$ ).

No significant differences were observed between studied groups in length of hospital stay(mean 4.7 days in balloon group and 5.4 days in control group or site of postoperative admission (intensive care unit or high dependency unit) (Fig 7).

In terms of surgical complications; there was no statistical significance differences between studied groups in frequency of different maternal complication (Table 5), also there were no reported maternal or fetal complication related to the use of endovascular catheters. 
Table (1): Basic criteria of the two studied groups:

\begin{tabular}{|c|c|c|c|c|c|c|}
\hline Variable & \multicolumn{2}{|c|}{$\begin{array}{c}\text { Balloon Group } \\
(n=15)\end{array}$} & \multicolumn{2}{|c|}{$\begin{array}{c}\text { Control Group } \\
(n=15)\end{array}$} & $\mathbf{t}$ & $\bar{p}$ \\
\hline $\begin{array}{l}\text { Age : (year) } \\
\text { Mean } \pm S D \\
\text { Range }\end{array}$ & \multicolumn{2}{|c|}{$\begin{array}{c}33.67 \pm 3.79 \\
28-44\end{array}$} & \multicolumn{2}{|c|}{$\begin{array}{c}34.73 \pm 4.36 \\
27-43\end{array}$} & 0.71 & $\begin{array}{l}0.48 \\
\text { NS }\end{array}$ \\
\hline $\begin{array}{l}\text { GA at delivery: (week) } \\
\text { Mean } \pm S D \\
\text { Range }\end{array}$ & \multicolumn{2}{|c|}{$\begin{array}{c}37.13 \pm 0.55 \\
36-38\end{array}$} & \multicolumn{2}{|c|}{$\begin{array}{c}37.1 \pm 0.39 \\
36.5-38\end{array}$} & 0.19 & $\begin{array}{l}0.85 \\
\text { NS }\end{array}$ \\
\hline Variable & No & $\%$ & No & $\%$ & $\chi^{2}$ & $\mathbf{P}$ \\
\hline $\begin{array}{l}\text { Gravidity: } \\
2-4 \\
5-7 \\
8 \\
\end{array}$ & $\begin{array}{l}7 \\
6 \\
2 \\
\end{array}$ & $\begin{array}{c}46.7 \\
40 \\
13.3 \\
\end{array}$ & $\begin{array}{l}7 \\
8 \\
0 \\
\end{array}$ & $\begin{array}{c}46.7 \\
53.3 \\
0 \\
\end{array}$ & 2.29 & $\begin{array}{l}0.32 \\
\text { NS }\end{array}$ \\
\hline $\begin{array}{l}\text { Parity: } \\
1-3 \\
4-6\end{array}$ & $\begin{array}{c}11 \\
4\end{array}$ & $\begin{array}{l}73.3 \\
26.7\end{array}$ & $\begin{array}{c}12 \\
3\end{array}$ & $\begin{array}{l}80 \\
20\end{array}$ & 0.19 & $\begin{array}{l}0.67 \\
\text { NS }\end{array}$ \\
\hline $\begin{array}{l}\text { Previous CS: } \\
1-2 \\
3-4 \\
5 \\
\end{array}$ & $\begin{array}{l}5 \\
8 \\
2 \\
\end{array}$ & $\begin{array}{l}33.3 \\
53.3 \\
13.3 \\
\end{array}$ & $\begin{array}{l}7 \\
7 \\
1 \\
\end{array}$ & $\begin{array}{r}46.7 \\
46.7 \\
6.7 \\
\end{array}$ & 0.73 & $\begin{array}{l}0.69 \\
\text { NS }\end{array}$ \\
\hline $\begin{array}{l}\text { Other operation: } \\
\text { No } \\
\text { D \& } C \\
\text { Myomectomy } \\
\text { Rupture uterus }\end{array}$ & $\begin{array}{l}9 \\
5 \\
0 \\
1\end{array}$ & $\begin{array}{c}60 \\
33.3 \\
0 \\
6.7\end{array}$ & $\begin{array}{l}9 \\
5 \\
1 \\
0\end{array}$ & $\begin{array}{c}60 \\
33.3 \\
6.7 \\
0 \\
\end{array}$ & 2 & $\begin{array}{l}0.57 \\
\text { NS }\end{array}$ \\
\hline
\end{tabular}

SD: Stander deviation t: Independent t test

GA: Gestational age

Table (2): Ultrasound \& intraoperative diagnosis of studied groups:

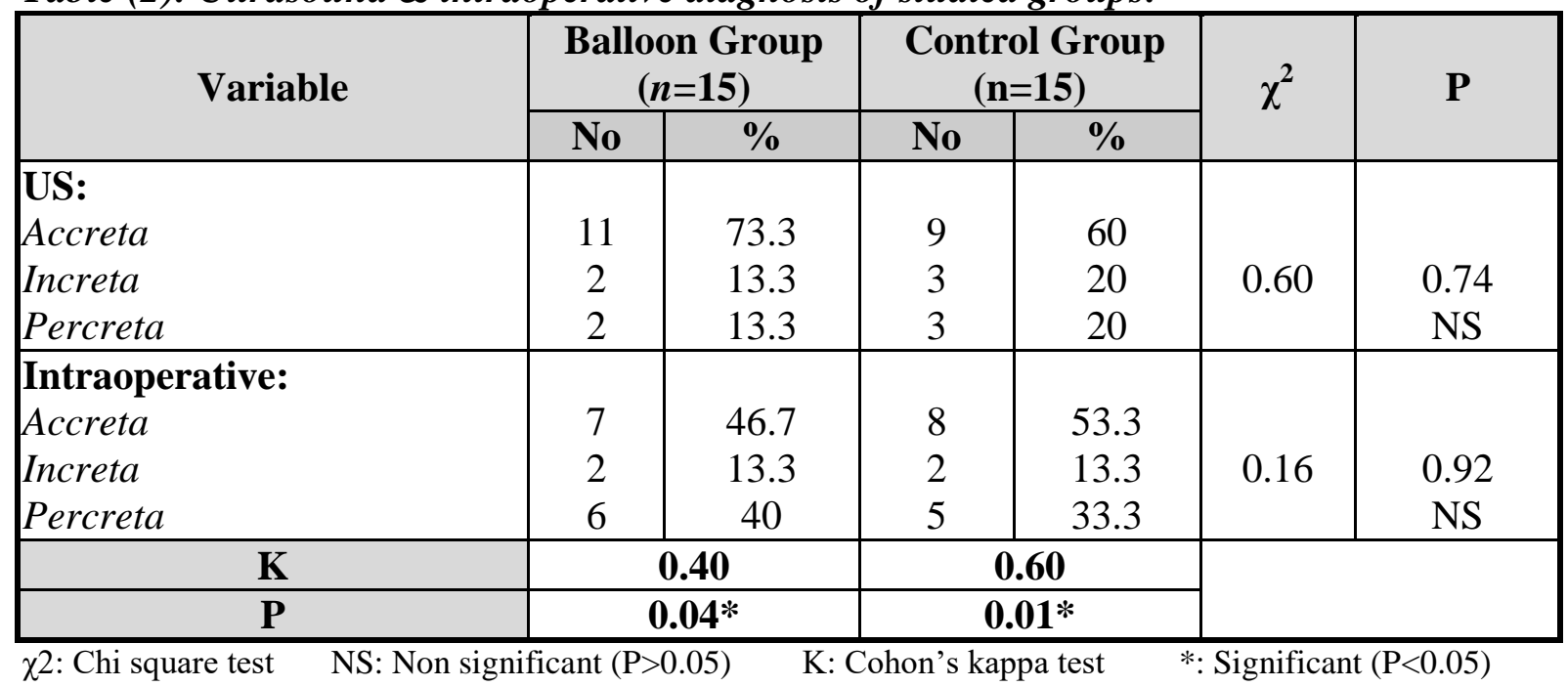


Table (3): Operative data of studied groups:

\begin{tabular}{|c|c|c|c|c|}
\hline Variable & $\begin{array}{c}\text { Balloon Group } \\
(n=15)\end{array}$ & $\begin{array}{c}\text { Control Group } \\
(n=15)\end{array}$ & Test & p \\
\hline $\begin{array}{l}\text { Operation time:(min) } \\
\text { Mean } \pm S D \\
\text { Range }\end{array}$ & $\begin{array}{c}141 \pm 42.78 \\
90-220\end{array}$ & $\begin{array}{c}144.33 \pm 43.61 \\
90-250\end{array}$ & $\begin{array}{c}\mathbf{t} \\
0.21\end{array}$ & $\begin{array}{l}0.83 \\
\mathrm{NS}\end{array}$ \\
\hline $\begin{array}{l}\text { Balloon insertion time:(min) } \\
\text { Mean } \pm S D \\
\text { Range }\end{array}$ & $\begin{array}{c}18.13 \pm 2.36 \\
15-22\end{array}$ & ------ & ---- & ----- \\
\hline $\begin{array}{l}\text { Fluoroscopy time:(min) } \\
\text { Mean } \pm S D \\
\text { Range }\end{array}$ & $\begin{array}{r}9.20 \pm 1.2 \\
8.30-10.30\end{array}$ & & & \\
\hline $\begin{array}{l}\text { Occlusion time:(min) } \\
\text { Mean } \pm S D \\
\text { Range }\end{array}$ & $\begin{array}{c}116.33 \pm 39.03 \\
70-190\end{array}$ & -------- & ---- & ----- \\
\hline $\begin{array}{l}\text { ABL:(Gross Formula })(\mathbf{m l}) \\
\text { Mean } \pm S D \\
\text { Median } \\
\text { Range }\end{array}$ & $\begin{array}{c}1210.67 \pm 495.27 \\
1200 \\
1000-2400\end{array}$ & $\begin{array}{c}1615.4 \pm 618 \\
1600 \\
1100-3400\end{array}$ & $\begin{array}{l}\text { MW } \\
2.17\end{array}$ & 0.03* \\
\hline $\begin{array}{l}\text { EBL: }(\mathbf{m l}) \\
\text { Mean } \pm S D \\
\text { Median } \\
\text { Range }\end{array}$ & $\begin{array}{c}1315 \pm 504.43 \\
1200 \\
800-2500\end{array}$ & $\begin{array}{c}1766.7 \pm 768.97 \\
1700 \\
850-3500\end{array}$ & $\begin{array}{l}\text { MW } \\
2.01\end{array}$ & $0.04 *$ \\
\hline $\begin{array}{l}\text { HB change }:(\mathbf{g m} / \mathbf{d l}) \\
\text { Mean } \pm S D \\
\text { Median } \\
\text { Range }\end{array}$ & $\begin{array}{c}1.15 \pm 0.53 \\
1.2 \\
0.5-2.1\end{array}$ & $\begin{array}{c}1.79 \pm 0.96 \\
1.5 \\
0.7-4\end{array}$ & $\begin{array}{l}\text { MW } \\
1.99\end{array}$ & $0.04 *$ \\
\hline $\begin{array}{l}\text { Bilateral Ligation of IIA: } \\
\operatorname{Yes} N(\%)\end{array}$ & ------ & $6(40 \%)$ & ---- & ---- \\
\hline $\begin{array}{l}\text { SD: Stander deviation } \\
\text { NS: Non significant }(\mathrm{P}>0.05) \\
\text { EBL: Estimated blood loss }\end{array}$ & $\begin{array}{l}\text { MW: Mann Whitney test } \\
\text { *: Significant }(\mathrm{P}<0.05) \\
\text { HB: Hemoglobin }\end{array}$ & $\begin{array}{l}\mathrm{t}: \text { Independent } \mathrm{t} \text { te } \\
\text { ABL: Actual bloo } \\
\text { IIA: Internal iliac }\end{array}$ & & \\
\hline
\end{tabular}

Table (4): Intravenous fluids and blood transfusion among studied groups:

\begin{tabular}{|c|c|c|c|c|c|c|}
\hline Variable & \multicolumn{2}{|c|}{$\begin{array}{c}\text { Balloon Group } \\
(n=15)\end{array}$} & \multicolumn{2}{|c|}{$\begin{array}{c}\text { Control Group } \\
(n=15)\end{array}$} & $\mathbf{t}$ & $\mathbf{p}$ \\
\hline \begin{tabular}{|l|} 
IV fluid: \\
Crystalloid \\
Mean $\pm S D$ \\
Range \\
Colloid \\
Mean $\pm S D$ \\
Range
\end{tabular} & \multicolumn{2}{|c|}{$\begin{array}{c}1400 \pm 387.30 \\
1000-2500 \\
(n=7) \\
571.43 \pm 188.98 \\
500-1000\end{array}$} & \multicolumn{2}{|c|}{$\begin{array}{c}1766.7 \pm 677.88 \\
1000-3500 \\
(n=7) \\
582.36 \pm 163.45 \\
500-1000\end{array}$} & $\begin{array}{c}1.82 \\
0.004\end{array}$ & $\begin{array}{l}0.08 \\
\mathrm{NS} \\
0.99 \\
\mathrm{NS}\end{array}$ \\
\hline Variable & No & $\%$ & No & $\%$ & $\chi^{2}$ & $\overline{\mathbf{P}}$ \\
\hline $\begin{array}{l}\text { RBCs: (Unit) } \\
1-3 \\
4-6 \\
\geq 7\end{array}$ & $\begin{array}{l}11 \\
4 \\
0\end{array}$ & $\begin{array}{c}73.3 \\
26.7 \\
0\end{array}$ & $\begin{array}{l}5 \\
6 \\
4\end{array}$ & $\begin{array}{c}33.3 \\
40 \\
26.7\end{array}$ & 6.65 & $0.03 *$ \\
\hline $\begin{array}{l}\text { Plasma: (unit) } \\
N o \\
1-2 \\
3-4\end{array}$ & $\begin{array}{l}7 \\
7 \\
1\end{array}$ & $\begin{array}{c}46.7 \\
46.7 \\
6.7\end{array}$ & $\begin{array}{l}2 \\
7 \\
6\end{array}$ & $\begin{array}{c}13.3 \\
46.7 \\
40\end{array}$ & 6.35 & $0.04 *$ \\
\hline
\end{tabular}

SD: Stander deviation

NS: Non significant $(\mathrm{P}>0.05)$
MW: Mann Whitney test

*: Significant $(\mathrm{P}<0.05)$ $\chi 2$ : Chi square test 


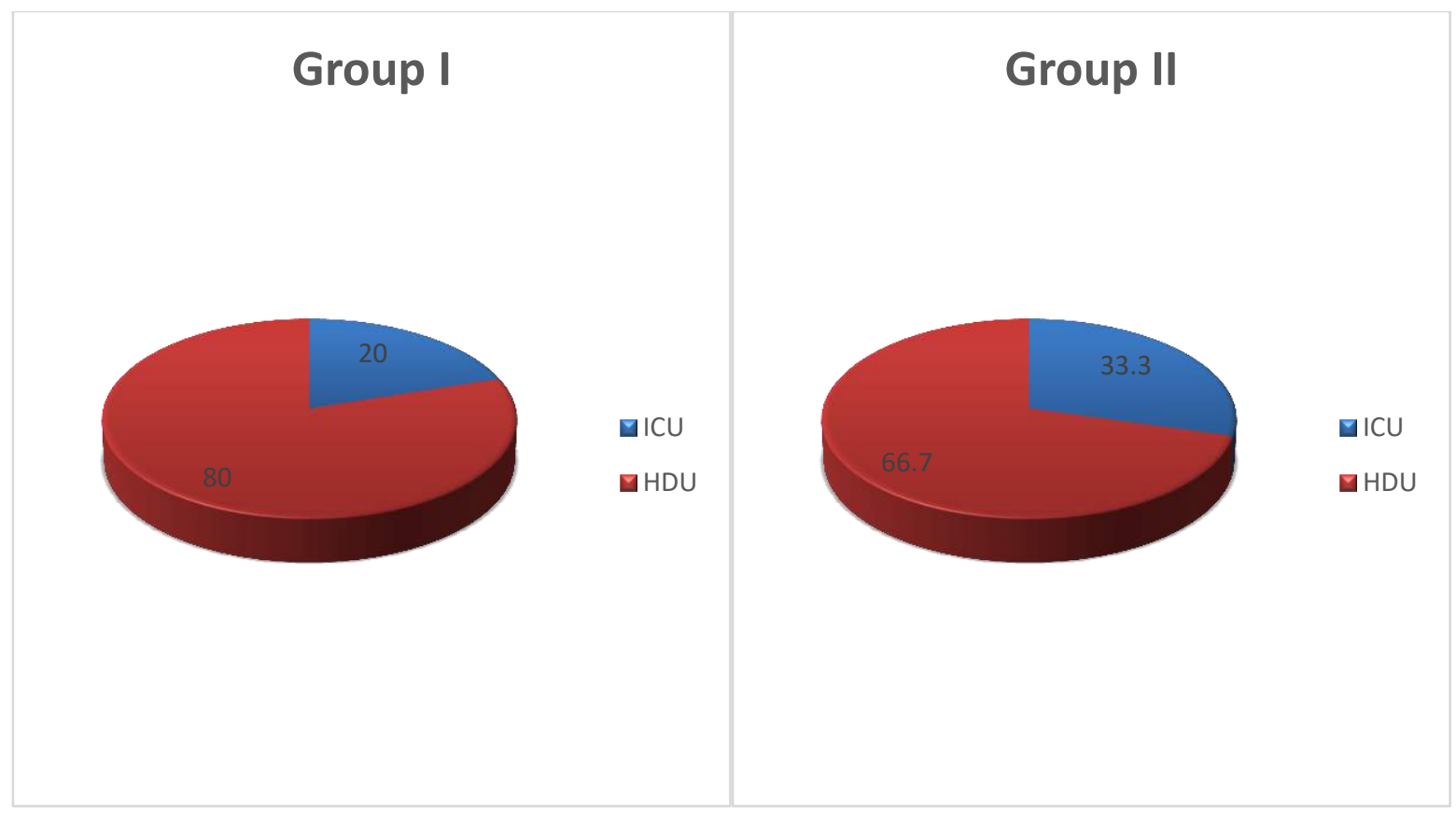

Fig. (7): Postoperative admission among studied groups.

Table (5): Maternal and fetal complications among studied groups:

\begin{tabular}{|c|c|c|c|c|c|c|}
\hline \multirow[t]{2}{*}{ Variable } & \multicolumn{2}{|c|}{$\begin{array}{c}\text { Balloon Group } \\
(n=15)\end{array}$} & \multicolumn{2}{|c|}{$\begin{array}{c}\text { Control Group } \\
(n=15)\end{array}$} & \multirow[t]{2}{*}{$\chi^{2}$} & \multirow[t]{2}{*}{$\mathbf{P}$} \\
\hline & No & $\%$ & No & $\%$ & & \\
\hline 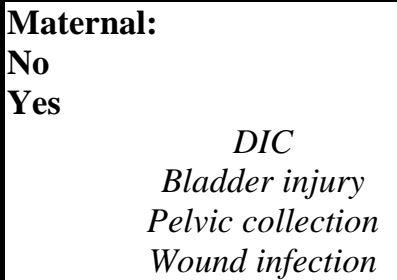 & $\begin{array}{c}11 \\
4 \\
0 \\
3 \\
1 \\
1\end{array}$ & $\begin{array}{c}73.3 \\
26.7 \\
0 \\
20 \\
6.7 \\
0\end{array}$ & $\begin{array}{l}9 \\
6 \\
1 \\
3 \\
1 \\
2\end{array}$ & $\begin{array}{c}60 \\
40 \\
6.7 \\
20 \\
6.7 \\
13.3\end{array}$ & 0.60 & $\begin{array}{c}0.44 \\
\text { NS } \\
\\
0.82 \\
\text { NS }\end{array}$ \\
\hline $\begin{array}{l}\text { Neonatal: } \\
\text { No } \\
\text { Yes (NICU admission) }\end{array}$ & $\begin{array}{c}12 \\
3\end{array}$ & $\begin{array}{l}80 \\
20\end{array}$ & $\begin{array}{c}11 \\
4\end{array}$ & $\begin{array}{l}73.3 \\
26.7\end{array}$ & 0.19 & $\begin{array}{l}0.67 \\
\text { NS }\end{array}$ \\
\hline
\end{tabular}

$\chi 2$ : Chi square test $\quad$ NS: Non significant $(\mathrm{P}>0.05) \quad$ NICU: Neonatal intensive care unit

\section{DISCUSSION}

The incidence of placenta accreta is rising rapidly in the United States, affecting an estimated 1 in 533 pregnancies (9). The strongest factor contributing to this rapid rise is the increased incidence of cesarean deliveries over the past 20 years. It increases the likelihood of significant morbidity and mortality for both mother and newborn, especially if diagnosed at the time of delivery (3).

Antenatal diagnosis of placenta accreta/percreta is associated with reduced levels of blood loss and a reduced need for blood transfusion. All patients in this study were diagnosed with ultrasonography and power DOPPLER US or coupled with MRI evaluation. There were statistical significant agreement between US and interoperation results in both studied groups ( $\mathrm{p}$ value 0.04 in group $\mathrm{A}$ and 0.01 in group B) and in 3 cases only we confirm the diagnosis using MRI. Calì $\mathbf{G}$ et al. (10) and Shih JC et al. (11) have confirmed the possibility of differentiation between serious forms of placenta percreta and less severe forms of placenta 
accreta/increta using grey scale U\&S and power Doppler U\&S.

Current management strategies for abnormal placentation include caesarean hysterectomy with a high risk of intraoperative hemorrhage or conservative techniques without hysterectomy, leaving the placenta in situ which is associated risk of sepsis, delayed hemorrhage and/or additional treatment (12).

Different techniques have been developed to decrease intraoperative blood loss depend on reducing pelvic circulation, primarily of the internal iliac arteries for disruption of the arterial blood supply to the uterus and preserving the blood supply to other pelvic structures. This has been accomplished either by temporary balloon occlusion or by intraoperative ligation of the internal iliac arteries a technique to reduce the pulse pressure distal to the level of occlusion, thus minimizing blood loss during cesarean delivery in placenta accreta (13).

In almost two thirds of cases in group (A) patients, blood loss was less than $1000 \mathrm{mls}$, the commonly accepted level for postpartum hemorrhage, there was significant decrease in mean estimated blood loss in balloon catheter group $(1315 \mathrm{mls})$ and significant decrease in amount of blood ( $\mathrm{p}$ value 0.03 ) and plasma transfusion ( $p$ value 0.04 ) in comparison to non-balloon group (mean estimated blood loss $=1766 \mathrm{mls}$ ), this correlate favorably with the estimated blood loss of $1671 \mathrm{mls}$ and $2011 \mathrm{mls}$ reported by Carnevale et al.(6) and Tan et al.(14) respectively. Also Calì $\mathbf{G}$ et al. (10) found significant decrease in mean estimated blood loss in balloon catheter group $(933 \mathrm{mls})$ in comparison to non-balloon group (1507mls).

On the other hand in a case control study, Shrivastava et al. (15) observed no improvement in the outcomes of women treated with pre-operative balloon catheters plus hysterectomy, compared with the outcomes of women treated with hysterectomy alone. Also Bodner et al.(16) concluded that temporary balloon occlusion and prophylactic embolization failed to reduce blood loss in the intraoperative stage in patients with placental accreta with average blood loss $2.8 \mathrm{~L}$ in endovascular group and $2.5 \mathrm{~L}$ in control group.

Presence of collateral vessels in the gravid uterus could explain some failures of occlusive balloons and overall blood loss could be contributed by collateral circulation from cervical, ovarian, rectal, femoral, lumbar and sacral arteries (2).

There are suggestions that occlusion of the common iliac vessels (17) or infra renal aorta $(18,19)$ may be a better option to reduce the amount of blood loss, by additional blockage of the supply from the external iliac vessels and aorta and easier to lodge the balloons in these locations as opposed to the internal iliac arteries; However, caution must be used when inflating the balloons in these sites since this could lead to reperfusion injury, thrombosis, and/or embolism of the lower extremities(17). In this study, the occlusions of the internal iliac arteries seem equally effective in reduction of blood loss.

On the other hand we don't demonstrate any significant change in operation time between two groups (mean $141 \mathrm{~min}$ in group A and $144 \mathrm{~min}$ in group B)or in post-operative admission to ICU or HDU or in total duration of hospital stay between two groups (average 4.7 days in group A, 5.4 days in group B); this time was for early diagnosis of thrombosis in group A and risk of bleeding in both groups; Also Tan et al. (14) found no significant differences in length of hospital or ICU stay although the duration of surgery was significantly less in the study group.

There were no reported complications associated with the use of balloon catheters 
in group (A) patients as well as Yiap $\mathbf{L}$ et al. (20) case series. On the other hand Sewell et al. (21) have reported acute limb ischemia secondary to popliteal arterial thrombus, Greenberg et al. (22) also reported a case developed common and external iliac artery thrombosis following temporary balloon occlusion of the internal iliac arteries for placenta accrete, also Thon et al. (23) reported a case developed extensive hemorrhage leading to perioperative hypovolemic cardiac arrests and other case developed bilateral pseudo aneurysms.

These complications observed may be caused due to extended length of time in surgery, the intrinsic hypercoagulability state that is observed at the end of pregnancy or the balloons moved position during inflation or deflation (23). In this study continuous irrigation of the sheath with saline solution throughout the entire procedure also helps to reduce thrombotic complications.

There was no statistical significance difference between the two studied groups in frequency of different maternal complication. There were 6 cases of bladder injuries 3 in each group, all were placenta percreta; 4 injuries occur inadvertent during bladder dissection which was avoided in later cases by using bladder filling technique and 2 injuries were inevitable due to placental invasion to the posterior bladder wall .Intraoperative urologic consultation was done in these cases for bladder repair and Foleys catheter was kept for 10 days.

Also there was a case of placenta percreta in the control group that complicated by DIC due to massive obstetric hemorrhage $(\mathrm{ABL}=3.5 \mathrm{~L})$, bilateral IIL artery and abdominal packing to control bleeding and the patient was transferred to ICU after that.13 unit packed RBCS, 4 unit plasma and 2 cryoprecipitate was transfused to the patient. The wound was complicated by infection and managed by secondary sutures 2 weeks postoperative. There were two cases of pelvic collection one in each group that relieved by antibiotic and U\&S guided drainage; all patients were going well after that.

In this study the average time for obtaining an access through the punctures of common femoral arteries in 15 patients who have undergone temporary balloon occlusion was 18 minutes, and the average time of maternal and fetal exposure to fluoroscopy varied from $8.30 \mathrm{~min}$ and 10.30 min. Kidney et al. (24) reported that the average time for balloon insertion in five patients was $30 \mathrm{~min}$, and the average time of maternal and fetal exposure to fluoroscopy varied from $4.30 \mathrm{~min}$ to 8.12 min. In Carnevale et al. (6) the average time of fluoroscopy was $7.30 \mathrm{~min}$.

Questions surrounding maternal and fetal radiation exposure would undoubtedly arise during treatment. Deterministic side effects (fetal growth restriction, malformation, mental retardation) are no longer a major concern for the term fetus (25).

In this study image acquisition was performed by digital subtraction at a rate of 1 frame/s, using road mapping for selective catheterization, thus minimizing the radiation dose. The average fetal radiation dose in our patients was 2.6 rads. The median fetal dose in the study by (Levine et al. (26) was 6.1 rads. It has been estimated that there is a $99.5 \%$ likelihood of a child never developing childhood cancer following fetal radiation doses up to 10 rads. No congenital defects that could be related to the radiation dose were detected within first year in the 1 st 5 cases. Also there was no statistical significance difference between the two studied groups in frequency of admission to NICU or in APGAR score.

\section{CONCLUSION}

In conclusion, this study suggests that preoperative prophylactic balloon occlusion of bilateral internal iliac arteries 
reduces both blood loss and transfusion requirement in patients with placenta accreta, scheduled to undergo elective caesarean hysterectomy. It is an adjunct to be considered in the management of a modern day obstetric problem, although we are cautious about generalizing its benefit without larger, randomized trials.

\section{REFERENCES}

1. The American College of Obstetricians and Gynecologists (2012): Committee Opinion No. 529: Placenta accreta. Obstet Gynecol; 120(1): 207-11.

2. Dilauro MD, Dason S, Athreya S. (2012): Prophylactic balloon occlusion of internal iliac arteries in women with placenta accreta: literature review and analysis. Clin radiol; 67(6): 515-20.

3. Warshak CR, Ramos GA, Eskander R, et al.(2010): Effect of predelivery diagnosis in 99 consecutive cases of placenta accreta. Obstet Gynecol; 115:65-9.

4. Sentilhes L, Goffinet F, Kayem G (2013): Management of placenta accreta. Acta Obstet Gynecol Scand; 92(10): 1125-34.

5. Dubois J, Garel L, Grignon $A$ et al (1997): Placenta percreta: balloon occlusion and embolization of the internal iliac arteries to reduce intraoperative blood losses. Am J Obstet Gynecol; 176(3): 723-6.

6. Carnevale FC, Kondo MM, de Oliveira Sousa W, Jr. et al (2011): Perioperative temporary occlusion of the internal iliac arteries as prophylaxis in cesarean section at risk of hemorrhage in placenta accreta. Cardiovasc Intervent Radiol; 34(4): 75864.

7. Gross JB (1983): Estimating Allowable Blood Loss: Corrected for Dilution. Anesthesiology 1983; 58(3): 277-80.

8. Ajjammanavar V, Jayashree $S$, Amrutha B (2016): Blood loss assessment in abdominal hysterectomy: how accurate Int J Reprod Contracept Obstet Gynecol 2016;5 : 306-9.

9. Wu S, Kocherginsky M, Hibbard JU. Abnormal placentation (2005): twenty- year analysis. Am J Obstet Gynecol; 192:1458-61.

10. Calì G, Giambanco L, Puccio G, Forlani F (2013): Morbidly adherent placenta: evaluation of ultrasound diagnostic criteria and differentiation of placenta accreta from percreta. Ultrasound Obstet Gynecol; 41(4):406-12.

11. Shih JC, Palacios, Jaraquemada JM (2009): Role of three- dimensional power Doppler in the antenatal diagnosis of placenta accreta: comparison with grayscale and color Doppler techniques. Ultrasound Obstet Gynecol; 33(2):193203.

12. Bretelle F, Courbiere B, Mazouni C, et al (2007): Management of placenta accreta: morbidity and outcome. Eur $\mathrm{J}$ Obstet Gynecol Reprod Biol; 133:34-9.

13. Darwish HS, Zaytoun HA, Kamel HH, Habash YH (2014): Prophylactic preoperative balloon occlusion of hypogastric arteries in abnormal placentation; 5 years' experience. The Egyptian Journal of Radiology and Nuclear Medicine; 45(2-3):751-9.

14. Tan C H, Tay K H, Sheah K, et al. (2007): Perioperative endovascular internal iliac artery occlusion balloon placement in management of placenta accreta. AJR Am J Roentgenol; 189:1158-1163.

15. Shrivastava $V$, Nageotte $M$, Major $C$, Haydon M, Wing D (2007): Casecontrol comparison of caesarean hysterectomy with and without prophylactic placement of intravascular balloon catheters for placenta accreta. Am J Obstet Gynecol; 197:402 e401-405.

16. Bodner LJ, Nosher JL, Gribbin C, Siegel RL, Beale S, Scorza W(2006): Balloon-assisted occlusion of the internal iliac arteries in patients with placenta accreta/ percreta. Cardiovasc Intervent Radiol; 29:354-61.

17. Shih JC, Liu KL, Shyu MK (2005): Temporary balloon occlusion of the common iliac artery: new approach to bleeding control during cesarean hysterectomy for placenta percreta. Am J 
Obstet Gynecol ; 193:1756e8. doi:10.1016/j.ajog.2005.08.033.

18. Masamoto $H$, Uehara $H$, Gibo $M$, Okubo E, Sakumoto K,Aoki Y(2009): Elective use of aortic balloon occlusion in cesarean hysterectomy for placenta previa percreta. Gynecol Obstet Invest.; 67:92-5.

19. Bell-Thomas SM, Penketh RJ, Lord RH, Davies NJ, Collis R (2003): Emergency use of a transfemoral aortic occlusion catheter to control massive haemorrhage at caesarean hysterectomy. BJOG; 110(12):1120-1122.

20. Yiap Loong Tan1, Haris Suharjono2, Nina Lee Jing Lau2, Hian Yan Voon2 (2016): Prophylactic bilateral internal iliac artery balloon occlusion in the management of placenta accreta: A 36month review Med J Malaysia Vol 71 No 3.

21. Sewell MF, Rosenblum D, Ehrenberg H (2006): Arterial embolus during common iliac balloon catheterization at cesarean hysterectomy.

ObstetGynecol;108:746e8.doi:10.1097/01 .AOG.0000201992.80130.2c.

22. Greenberg JI, Suliman A, Iranpour $P$ (2007): Prophylactic balloon occlusion of the internal iliac arteries to treat abnormal placentation: a cautionary case. Am J Obstet Gynecol; 197: 470.e1-4.

23. Thon S, McLintic A, Wagner Y (2011): Prophylactic endovascular placement of internal iliac occlusion balloon catheters in parturients with placenta accreta: a retrospective case series. Int $\mathrm{J}$ Obstet Anesth; 20(1): 64-70.

24. Kidney DD, Nguyen AM, Ahdoot D, Bickmore D, Deutsch LS, Majors C (2001): Prophylactic perioperative hypogastric artery balloon occlusion in abnormal placentation. AJR Am J Roentgenol176:1521-1524.

25. Teixidor Vinas M, Chandraharan E, Moneta MV et al (2014): The role of interventional radiology in reducing haemorrhage and hysterectomy following caesarean section for morbidly adherent placenta. Clin Radiol; 69(8): e345-51.

26. Levine AB, Kuhlman $K$, Bonn $J$. Placenta accreta (1999): comparison of cases managed with and without pelvic artery balloon catheters. J Matern Fetal Med; 8:173e6. Doi: 2-V. 